\title{
The Practice of Acupuncture: Who Are the Providers and What Do They Do?
}

Karen J. Sherman, $\mathrm{PbD}^{1,2}$

Daniel C. Cherkin, $P b D^{1,3}$

David M. Eisenberg, $M D^{4}$

Janet Erro, RN, MN, PNP ${ }^{1}$

Andrea Hrbek ${ }^{4}$

Richard A. Deyo, MD, MPH

'Center for Health Studies, Group Health Cooperative, Seattle, Wash

${ }^{2}$ Department of Epidemiology, University of Washington, Seattle, Wash

${ }^{3}$ Departments of Family Medicine and Health Services, University of Washington, Seattle, Wash

${ }^{4}$ Harvard Medical School Osher Institute and Division for Research and Education in Complementary and Integrative Medical Therapies, Harvard Medical School, Boston, Mass

${ }^{5}$ Departments of Medicine and Health Services, University of Washington, Seattle, Wash

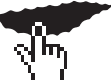

MORE ONLINE

MORE ONLINE
www.annfammed.org
Conflicts of interest: none reported

\section{CORRESPONDING AUTHOR}

Karen J. Sherman, PhD

Center for Health Studies

Group Health Cooperative

1730 Minor Ave, Suite 1600

Seattle, WA 98101

sherman.k@ghc.org

\begin{abstract}
PURPOSE This study provides basic information about the training and practices of licensed acupuncturists.
\end{abstract}

METHODS Randomly selected licensed acupuncturists in Massachusetts and Washington state were interviewed and asked to record information on 20 consecutive patient visits.

RESULTS Most acupuncturists in both states had 3 or 4 years of academic acupuncture training and had received additional "postgraduate" training as well. Acupuncturists treated a wide range of conditions, including musculoskeletal problems (usually back, neck, and shoulder) (33\% in Massachusetts and $47 \%$ in Washington), general body symptoms (12\% and $9 \%$, respectively) such as fatigue, neurological problems (10\% and $12 \%$, respectively) (eg, headaches), and psychological complaints (10\% and $8 \%$, respectively) (especially anxiety and depression). Traditional Chinese medicine (TCM) was the predominant style of acupuncture used in both states $(79 \%$ and $86 \%$, respectively). Most visits included a traditional diagnostic assessment (more than 99\%), regular body acupuncture $(95 \%$ and $93 \%$, respectively), and additional treatment modalities $(79 \%$ and $77 \%$, respectively). These included heat and lifestyle advice (66\% and $65 \%$, respectively), most commonly dietary advice and exercise recommendations. Chinese herbs were used in about one third of visits. Although most patients self-referred to acupuncture, about one half received concomitant care from a physician. Acupuncturists rarely communicated with the physicians of their patients who were providing care for the same problem.

CONCLUSIONS This study contributes new information about acupuncturists and the care they provide that should be useful to clinicians interested in becoming more knowledgeable about complementary or alternative medical therapies available to their patients.

Ann Fam Med 2005;3:151-158. DOI: 10.1370/afm.248.

\section{INTRODUCTION}

7 he use of complementary and alternative medicine (CAM) therapies, including provider-based therapies, has grown in the United States since the 1950s. ${ }^{1}$ Although acupuncture has been available in various Chinatowns in the United States since the mid 1800s, it has been a relative latecomer to the general American health care scene, growing rapidly since the 1970s, when Nevada and Oregon became the first states to license nonphysician acupuncturists. ${ }^{2}$ Currently, 51 acupuncture schools are accredited or are candidates for accreditation, ${ }^{3}$ and 42 states have statutes that allow the practice of acupuncture by nonphysicians. ${ }^{4}$ In addition, about 3,000 physicians in the United States are believed to practice acupuncture. ${ }^{2,5}$

Despite growth in the popularity of acupuncture and in the number of clinical studies evaluating its effectiveness for various conditions, little is known about the training or practices of acupuncturists. This study ${ }^{6}$ presents new information about the demographic and training characteristics of licensed acupuncturists, the reasons patients seek their care, the diagnostic 
processes they use, and the treatments and self-care recommendations they provide.

\section{METHODS}

The data summarized in this article were collected as part of a larger study of 4 CAM professions, including acupuncture. ${ }^{6,7}$ The goal of that study was to obtain data on 20 consecutive visits from 50 randomly selected acupuncturists in 1 Western state and in 1 Northeastern state. Acupuncturists were randomly sampled from state licensure listings in Washington (1998) and Massachusetts (1999). We excluded acupuncturists without identifiable telephone numbers and those not currently practicing. The proportion of ineligible practitioners was $38 \%$ in Massachusetts and 13\% in Washington. Almost all ineligible acupuncturists in Massachusetts lacked identifiable telephone numbers. The interview participation rate was $91 \%$ in Massachusetts and $89 \%$ in Washington.

Acupuncturists were first interviewed about their demographic, training, and practice characteristics. Those seeing at least 20 patients (visits) in a typical week were then invited to collect visit data. A sample of those seeing 10 to 19 patients per week were also invited to collect visit data. Acupuncturists seeing fewer than 10 patients per week, representing about $2 \%$ of all acupuncture visits, ${ }^{6}$ were not asked to collect visit data. Of the acupuncturists invited to collect visit data, 75\% in Massachusetts and $82 \%$ in Washington did so.

We obtained approval from the Group Health Cooperative, University of Washington, and Beth Israel-Deaconness institutional review boards. Visit data were collected between February and October in 1998 in Washington and between May and October 1999 in Massachusetts. Acupuncturists were given visit forms with unique identification codes for recording the data on 20 consecutive visits (even if the same patient was seen more than once) and were randomly assigned weekdays to begin data collection.

The 1-page visit forms were modeled after those used in the National Ambulatory Medical Care Survey (NAMCS). ${ }^{8}$ Copies of these forms are available from the authors on request. Whenever possible, questions on the visit forms were identical to those in the NAMCS (eg, demographic characteristics, reason for visit, referral source, source of payment, visit disposition). New questions asked whether the patient was receiving care from a conventional medical physician for their primary problem and whether the acupuncturist had communicated with this physician. Additional special questions captured information about acupuncture diagnoses and treatments, including information on traditional East Asian medical diagnoses, styles of acu- puncture used, types of needling, use of heat and other adjunctive treatments, and lifestyle recommendations. We asked acupuncturists to record up to 5 "complaints, symptoms, or other reasons for this visit" using the patient's own words and listing the most important complaint or reason first. These data were classified using the NAMCS Reason for Visit Classification System, which distinguishes among symptoms, diseases, diagnostic/screening/preventive interventions, treatments, and injuries. ${ }^{8}$ Individual reasons for visit were then clustered into larger categories corresponding to International Classification of Diseases, Ninth Edition (ICD-9) chapters.

Analyses were performed using SAS version 8 (SAS Institute, Cary, NC). Chi-square tests were used to compare proportions and Kruskal-Wallis tests were used to compare medians in the acupuncturist analyses. In the visit analyses, each visit in the sample was weighted by the inverse of its sampling probability, which reflected both the chance that the particular acupuncturist participated and the estimated proportion of that acupuncturist's annual visits included in the study. ${ }^{6}$ Consequently, our results represent estimates of all visits made to acupuncturists in each state, except for the $2 \%$ of visits made to providers who saw fewer than 10 patients per week. In this 2-stage sampling design, we used SUDAAN software (Research Triangle Institute, Research Triangle, NC) to calculate standard errors and confidence intervals using Taylor series linearization. Because of the large sample sizes in both states (more than 1,200), the weighted percentages presented in the tables have small standard errors, generally between 0.5 and 2.5 percentage points and rarely exceeding 3 percentage points. As a result, moderate to large differences between the states were also statistically significant. The standard errors are therefore not included in the tables.

\section{RESULTS}

\section{Demographic and Training Characteristics of the Acupuncturists}

The demographic and training characteristics of acupuncturists in Massachusetts and Washington were generally similar (Table 1). Most acupuncturists had 3 or 4 years of academic acupuncture training $(57 \%$ in Massachusetts and $85 \%$ in Washington), which currently results in a master's degree. In addition, $43 \%$ in Massachusetts and 26\% in Washington had formal apprenticeships, with $84 \%$ lasting 1 to 3 years. Acupuncturists receiving some training outside the United States were most likely to have trained in China and England. Sixteen percent of the acupuncturists in Massachusetts held licenses in other health professions (usually nursing) compared with 33\% in Washington (most commonly massage, naturopathic medicine, or 
nursing). Almost all acupuncturists in Massachusetts and two thirds of those in Washington received some additional acupuncture training (average of 2.7 topics vs 1.6 topics, respectively), most often in Chinese herbs and Japanese acupuncture (Table 1).

\section{Characteristics of the Visits}

\section{Reasons for Visits}

Musculoskeletal problems of various types were the most common reasons patients sought care from acupuncturists, representing one third to one half of all visits (Table 2 ). Neurological symptoms (especially headaches), general body symptoms (including fatigue and allergies), and mental health problems (especially anxiety and depression) were also relatively common in both states, as was wellness care in Massachusetts In fact, acupuncturists treated problems associated with virtually all organ systems, at least occasionally.

Almost $75 \%$ of visits to acupuncturists in both states were for chronic problems. More than $70 \%$ of patients were self-referred. About one half of the patients were receiving concomitant medical care for their primary complaint, although only $10 \%$ had been referred by

their physicians. Acupuncturists stated that they had discussed their patients' care with the physicians of only about $50 \%$ of their physician-referred patients compared with only $12 \%$ of their other patients.

\section{Care During Visits to Acupuncturists}

Information about the styles of practice of acupuncture, diagnostic techniques, types of needling, and adjunctive treatments (including information on herbal safety) can be found as supplemental data in the Supplemental Appendix, available online only at: http://www. annfammed.org/cgi/content/full/3/2/151/DC1. ${ }^{9-19}$ Traditional Chinese medicine (TCM) is the predominant style of acupuncture used in both states (Table 3 ). TCM is characterized by strong needling sensations and use of multiple adjunctive treatments, including herbs. All visits included the use of TCM diagnostic techniques, typically traditional questioning (ie, "asking diagnosis"), taking the radial pulse, inspecting the patient visually, and examining the tongue (Table 4).

Regular body acupuncture was used in nearly all visits, with other styles of acupuncture much less common (Table 5). For most visits, acupuncturists reported attempting to "obtain $q i$ " (de di) at

Table 1. Demographic and Training Characteristics of Acupuncturists Licensed in Massachusetts (1999) and Washington (1998)

\begin{tabular}{|c|c|c|c|}
\hline \multirow[b]{2}{*}{ Characteristics } & \multicolumn{2}{|c|}{ Licensed Acupuncturists } & \multirow[b]{2}{*}{$P$ Value } \\
\hline & $\begin{array}{l}\text { Massachusetts } \\
\mathrm{N}=101\end{array}$ & $\begin{array}{l}\text { Washington } \\
N=116\end{array}$ & \\
\hline \multicolumn{4}{|l|}{ Demographic characteristics } \\
\hline Female, \% & 58.4 & 56.0 & .72 \\
\hline \multicolumn{4}{|l|}{ Race, \% } \\
\hline White, \% & 81.4 & 77.3 & .59 \\
\hline Asian, \% & 16.5 & 20.9 & \\
\hline Other, \% & 2.1 & 1.8 & \\
\hline Median age, years & 47 & 43 & $<.001$ \\
\hline \multicolumn{4}{|l|}{ Basic training } \\
\hline US only, \% & 67.3 & 74.1 & .37 \\
\hline US same state, \% & 59.4 & 56.0 & $.61 *$ \\
\hline US and foreign, \% & 18.8 & 12.1 & \\
\hline Foreign only, \% & 12.9 & 13.8 & \\
\hline Licensed in another health profession, \% & 15.8 & 32.8 & .004 \\
\hline Median years in acupuncture practice & 11 & 4 & $<.001$ \\
\hline \multicolumn{4}{|l|}{ Postgraduate training } \\
\hline At least one type, \% & 96.0 & 67.2 & $<.001$ \\
\hline Addictions (NADA certification), \% & 32.7 & 19.8 & .03 \\
\hline Chinese herbs, \% & 71.3 & 35.3 & $<.001$ \\
\hline Japanese acupuncture, \% & 48.5 & 19.0 & $<.001$ \\
\hline Oriental massage, \% & 40.6 & 12.9 & $<.001$ \\
\hline Nogier, \% & 16.8 & 6.0 & .011 \\
\hline Other (eg, pediatrics, qi gong), \% & 49.5 & 17.9 & $<.001$ \\
\hline
\end{tabular}

one or more needling sites $(64 \%$ in Massachusetts and 76\% in Washington). De qi is the characteristic dull, heavy, tingling, or warm sensation that the patient may feel after the needle is inserted and stimulated. Electrostimulation of needles was infrequent in both states $(12 \%$ of visits in Massachusetts and $14 \%$ in Washington).

More than $75 \%$ of acupuncture visits included one or more adjunctive treatments (Table 6). Almost one half of the treatments included the use of heat, usually with a lamp heat or by moxibustion (the burning of the mugwort plant Artemisia vulgaris on or just above acupuncture points or meridians), and nearly one third included the prescription of Chinese herbs.

About two thirds of the visits in both states included self-care recommendations, with about $25 \%$ including multiple recommendations. Dietary or nutritional counseling from the perspective of Chinese medicine and exercise were the most common recommendations, each occurring in 


\begin{tabular}{|c|c|c|c|c|c|c|}
\hline \multicolumn{4}{|c|}{$\begin{array}{c}\text { Massachusetts } \\
\text { ( } N=1,298 \text { Visits) }\end{array}$} & \multicolumn{3}{|c|}{$\begin{array}{c}\text { Washington } \\
\text { ( } N=1,263 \text { Visits) }\end{array}$} \\
\hline Categories* & & $\begin{array}{c}\text { Primary } \\
\text { Reason } \\
\%\end{array}$ & & Categories* & & \\
\hline Broad & & & & Broad & & \\
\hline 1. Musculoskeletal conditions & & 33.0 & & 1. Musculoskeletal conditions & & \\
\hline 2. General conditions & & 12.1 & & 2. Nervous system conditions & & \\
\hline $\begin{array}{l}\text { 3. Psychological and mental health } \\
\text { symptoms }\end{array}$ & & 10.4 & & 3. General conditions & & \\
\hline 4. Nervous system conditions & & 9.9 & & $\begin{array}{l}\text { 4. Psychological and mental health } \\
\text { symptoms }\end{array}$ & & \\
\hline 5. Respiratory system conditions & & 7.1 & & 5. Digestive conditions & & \\
\hline 6. Genitourinary system conditions & & 5.7 & & 6. Respiratory system conditions & & \\
\hline 7. Digestive conditions & & 4.9 & & 7. Genitourinary system conditions & & \\
\hline 8. Wellness ${ }^{\dagger}$ & & 3.9 & & 8. Cardiovascular system conditions & & \\
\hline 9. Cardiovascular system conditions & & 2.7 & & 9. Infectious disease conditions & & \\
\hline 10. Neoplasms & & 1.6 & & 10. Skin conditions & & \\
\hline Specific & $\begin{array}{c}\text { Primary } \\
\text { Reason } \\
\%\end{array}$ & & $\begin{array}{c}\text { Any } \\
\text { Reason } \\
\%\end{array}$ & Specific & $\begin{array}{c}\text { Primary } \\
\text { Reason } \\
\%\end{array}$ & $\begin{array}{c}\text { Any } \\
\text { Reason } \\
\%\end{array}$ \\
\hline 1. Back symptoms & 11.3 & & 17.8 & 1. Back symptoms & 17.0 & 25.3 \\
\hline 2. Anxiety or depression & 7.5 & & 16.7 & 2. Neck symptoms & 7.3 & 13.7 \\
\hline 3. Fatigue & 4.8 & & 11.8 & 3. Headache & 6.6 & 11.0 \\
\hline 4. Headache & 4.0 & & 6.2 & 4. Shoulder symptoms & 5.6 & 12.7 \\
\hline 5. Wellnesst & 3.9 & & 5.3 & 5. Anxiety or depression & 4.5 & 12.6 \\
\hline 6. Neck symptoms & 3.4 & & 8.2 & 6. Fatigue & 2.8 & 9.7 \\
\hline 7. Allergies to food, milk, NOS & 2.6 & & 4.4 & 7. Knee symptoms & 2.1 & 4.1 \\
\hline 8. Shoulder symptoms & 2.6 & & 7.9 & 8. Abdominal pain, cramps, distention & 2.0 & 3.4 \\
\hline 9. Other nervous system symptoms & 2.2 & & 3.1 & 9. Infectious disease & 2.0 & 3.7 \\
\hline 10. Problems of pregnancy or fertility & 2.0 & & 2.5 & 10. Allergies to food, milk, NOS & 1.9 & 3.8 \\
\hline
\end{tabular}

about one third of the visits in both states. Sitting or moving meditation was recommended during $21 \%$ of visits in Massachusetts and 14\% in Washington.

\section{DISCUSSION}

This study reports unique data on the demographic and training characteristics of licensed acupuncturists, on the patients they treat, and on their diagnostic and treatment methods. Unlike previous studies, our data derived from specific patient visits and not from practitioner estimates. ${ }^{20-22}$ Other strengths of the study are the inclusion of 2 geographically separated states in parts of the country where acupuncture use is relatively common, random sampling of licensed providers, relatively high response rates, and large sample sizes. The main limitation is that we collected data from only 2 states.

Acupuncture statutes and their interpretation vary widely among states, with some permitting only acu- puncture needling and others allowing modalities that extend beyond the boundaries of traditional East Asian medicine. ${ }^{23}$ Unlike a few states, Massachusetts and Washington permit acupuncturists to function as independent health care practitioners. Massachusetts requires acupuncturists who prescribe herbs to have special certification in herbology, but Washington does not. Acupuncture training, however, is similar across the United States, largely because of the requirement by most states that applicants pass the national certification examination administered by the National Commission for the Certification of Acupuncture and Oriental Medicine. ${ }^{7}$

Most acupuncturists are not physicians, but acupuncture is also practiced by some biomedically trained providers. ${ }^{21,24,25}$ Although additional training for such providers is not required in most states, ${ }^{5}$ special training programs (usually 200 to 300 hours) have been developed for physicians, and many chiropractic colleges offer elective training in acupuncture. ${ }^{24}$ 
Table 3. Styles of Practice of Acupuncturists Licensed in Massachusetts (1999) and Washington (1998)

\begin{tabular}{lcc}
\hline & $\begin{array}{c}\text { Massachusetts } \\
\text { (N = 1,298 Visits) } \\
\text { Style of Practice* }\end{array}$ & $\begin{array}{c}\text { Washington } \\
\text { (N = 1,263 Visits) } \\
\%\end{array}$ \\
\hline French energetic & 1.1 & 5.1 \\
Japanese eclectic & 17.7 & 7.6 \\
Japanese meridian & 0.2 & 5.5 \\
Traditional Chinese medicine & 79.4 & 85.5 \\
Trigger point/Western style & 6.2 & 5.6 \\
Worsley 5 element & 12.2 & 5.0 \\
Other styles & 5.3 & 2.4 \\
Two or more styles used & 20.6 & 14.4 \\
\hline * Styles of practice are defined in the Appendix. & \\
\hline
\end{tabular}

Table 4. Diagnostic Techniques Performed by Acupuncturists Licensed in Massachusetts (1999) and Washington (1998)

\begin{tabular}{lcc}
\hline & $\begin{array}{c}\text { Massachusetts } \\
\text { (N = 1,298 Visits) } \\
\text { Diagnostic Technique* }\end{array}$ & $\begin{array}{c}\text { Washington } \\
\text { (N = 1,263 Visits) } \\
\text { \% }\end{array}$ \\
\hline At least 1 diagnostic technique & 99.7 & 99.8 \\
Abdominal diagnosis & 25.5 & 17.5 \\
Asking diagnosis & 89.8 & 93.1 \\
Auditory diagnosis & 22.7 & 19.3 \\
Muscle strength & 7.8 & 5.6 \\
Olfactory diagnosis & 17.1 & 16.4 \\
Point palpation/channel & 47.6 & 58.3 \\
diagnosis & & 81.4 \\
Pulse diagnosis & 90.5 & 75.0 \\
Tongue diagnosis & 70.5 & 77.8 \\
Visual diagnosis & 71.8 & 6.6 \\
Other & 0.9 & \\
\hline *Diagnostic techniques are defined in the Appendix. & \\
\hline
\end{tabular}

\section{Why Patients Visit Acupuncturists and Evidence for Efficacy}

Although musculoskeletal conditions are the most common reason people visit acupuncturists, they treat a broad range of other, mostly chronic, conditions. Generally, these are conditions for which Western medical care is often unsuccessful. Moreover, the list overlaps substantially with the most common conditions for which Americans seek CAM care in general. ${ }^{26}$ Our findings that musculoskeletal pain and headaches were common reasons for visits and that acupuncturists treated a broad range of conditions, at least occasionally, are consistent with studies using data from more specialized clinical settings. ${ }^{27-30}$

More than 40 meta-analyses and systematic reviews of the effectiveness of acupuncture for a host of conditions have been published, ${ }^{31}$ but nearly all are inconclusive because of the poor quality and small size of the primary studies. Nevertheless, at this point acupuncture appears to hold the most promise as an adjunct antiemetic for surgery and chemotherapy ${ }^{32}$ and for the treatment of headache..$^{33-35}$ In addition, most studies evaluating acupuncture for temporomandibular disorders, ${ }^{36}$ and shoulder pain ${ }^{37,38}$ have been positive.

Although results of studies of acupuncture for back and neck pain have been inconsistent, ${ }^{39-41}$ there is growing evidence that it might be helpful. ${ }^{42-45}$ Considering that few conventional or alternative treatments have proved very effective for back or neck pain, acupuncture may be a reasonable option for patients, especially if they are enthusiastic about trying it. In fact, Kaluaokalani et $\mathrm{al}^{46}$ found that patients with persistent back pain who were randomized to receive the therapy they preferred (ie, acupuncture or massage) were more likely to improve than those who received their less desired treatment. Fortunately, several large-scale randomized controlled trials are in progress that will soon provide more definitive answers about the effectiveness of acupuncture for common chronic pain conditions. ${ }^{47-50}$

\section{Safety of Acupuncture and Related Treatments}

Acupuncturists typically practiced acupuncture as a whole system of care, which included the use of traditional diagnostic techniques, acupuncture needling (typically with de di), one or more adjunctive treatments, and self-care recommendations. Chinese herbs were also often used, although no details were collected on the type of herbal preparations prescribed (eg, whether they were patent formulas or customized herbal formulations; whether patent herbs were manufactured in the United States or in China, or whether the herbs were imported directly from China or grown in the West).

Although needling and heat are relatively safe as long as sterile needles are used ${ }^{51-53}$ herbal medicine presents a number of potential risks for patients, $12,54,55$ including inappropriate dosages, herb-herb or herb-drug interactions, substitution of different herbs as a result of inaccurate translation, ${ }^{13}$ the contamination by or addition of toxic compounds and pharmaceutical medications, ${ }^{15-17,55,56}$ and the potential for delay of therapeutic options known to be effective. ${ }^{57}$ These risks can be reduced if Chinese herbs are prescribed only by acupuncturists with extensive training in herbal medicine 


\begin{tabular}{lcc|}
$\begin{array}{l}\text { Table 5. Types of Needling Performed by Acupuncturists } \\
\text { Licensed in Massachusetts (1999) }\end{array}$ & and Washington (1998) \\
\hline \multicolumn{4}{c}{$\begin{array}{c}\text { Massachusetts } \\
\text { (N = 1,298 visits) }\end{array}$} & $\begin{array}{c}\text { Washington } \\
\text { (N = 1,263 visits) } \\
\text { \% }\end{array}$ \\
\hline Type of Needling* & 2.1 & 1.8 \\
\hline None & 8.0 & 5.8 \\
Intradermal & 8.4 & 4.6 \\
lon pumping cords & 21.4 & 24.7 \\
Microsystem: ear & 2.3 & 4.2 \\
Microsystem: hand & 2.6 & 1.3 \\
Microsystem: scalp & 0.3 & 0.3 \\
Plum blossom & 95.1 & 93.3 \\
Regular body & 4.9 & 14.0 \\
Shallow & 6.1 & 2.9 \\
Other & 33.0 & 33.4 \\
Multiple types & \\
\hline * Types of needling are defined in the Appendix. & \\
\hline
\end{tabular}

\begin{tabular}{|c|c|c|}
\hline Treatment* & $\begin{array}{c}\text { Massachusetts } \\
\text { (N = 1,298 Visits) } \\
\%\end{array}$ & $\begin{array}{c}\text { Washington } \\
\text { ( } N=1,263 \text { Visits) } \\
\%\end{array}$ \\
\hline $\begin{array}{l}\text { At least } 1 \text { adjunctive } \\
\text { treatment }\end{array}$ & 79.4 & 76.9 \\
\hline $\begin{array}{l}\text { At least } 2 \text { adjunctive } \\
\text { treatments }\end{array}$ & 31.8 & 48.7 \\
\hline Heat & 49.4 & 44.2 \\
\hline Infrared lamp & 23.8 & 23.8 \\
\hline Moxibustion & 27.3 & 21.4 \\
\hline Other heat & 0.7 & 3.5 \\
\hline Multiple heat sources & 0.2 & 3.4 \\
\hline Acupoint bloodletting & 1.9 & 5.8 \\
\hline Cupping & 5.5 & 12.8 \\
\hline Gua sha & 1.9 & 1.7 \\
\hline Laser acupuncture & 1.3 & 2.2 \\
\hline Magnets & 16.7 & 2.6 \\
\hline Oriental herbs & 30.6 & 30.3 \\
\hline Oriental massage & 18.6 & 37.5 \\
\hline $\begin{array}{l}\text { Other (eg, liniment, } \\
\text { plasters) }\end{array}$ & 3.2 & 14.9 \\
\hline
\end{tabular}

other about the care of their patients. Possible barriers to such interdisciplinary communication include our observation that most patients who see both a physician and an acupuncturist for a particular condition were not referred to acupuncture by the physician, and that acupuncturists are trained to treat patients using a non-Western medical paradigm but are not always sufficiently trained to communicate their findings and treatment outcomes with conventional providers. In addition, we suspect that most acupuncturists, who are typically solo practitioners, lack office staff and appropriate record systems to assist with administrative tasks, including routine (and written) communication with other health care practitioners.

We believe that patients will benefit from increased communication between physicians and acupuncturists. Physicians can contribute to this process by asking patients about the type of care they are receiving from an acupuncturist, especially Chinese herbs. To better understand potential safety risks, including those that are due to adulterated products, dose-dependent toxicity or herb-drug interactions, physicians will benefit from conversations with acupuncturists about the nature of prescribed herbal formulas, especially when patients are taking concurrent prescription and over-the-counter medications. Physicians will also probably want to know how the acupuncturist is assessing the patient's response to treatment and whether the acupuncture treatments are helping the patient over a reasonable period. Some patients will want to try acupuncture only after consultation with their physician. In these circumstances, physicians can use the framework recommended by Eisenberg $^{58}$ to guide patients through the process of selecting a well-trained acupuncturist, jointly negotiating the treatment plan, and monitoring the effects of the treatment over time. who are aware of what other medications patients are taking and who obtain their herbs from Western sources (for more details on herbal safety, see the Appendix).

\section{Communication Between Acupuncturists and Physicians}

Acupuncture is an increasingly popular form of care used by patients who, about one half the time, are being treated simultaneously by a physician for the same problem. Yet we found that acupuncturists and medical doctors did not routinely communicate with each

\section{CONCLUSION}

While substantial barriers still exist to the full integration of acupuncture into the health care system (eg, variability between states in licensure and practice regulations, variable reimbursement practices by third party payers, lack of solid studies on efficacy for many frequently treated conditions) ${ }_{1}^{5}$ the information provided herein should be useful to physicians and other health care practitioners interested in advising their patients about acupuncture. 
To read or post commentaries in response to this article, see it online at http://www.annfammed.org/cgi/content/full/3/2/151.

Key words: Acupuncture; office visits; professional practice; alternative medicine

Submitted October 21, 2003; submitted, revised, May 5, 2004; accepted May 28, 2004.

Funding support: This project was supported by grants from the Group Health Foundation, Grants \#HS09565 and \#HS08194 from the Agency for Healthcare Policy and Research and Grant \#AR43441-04S1 from the National Institutes of Health. In-kind support was provided by the Centers for Disease Control and Prevention.

Acknowledgments: We thank the 35 members of the original acupuncture study team for data collection and Kristin Delaney for help with data analysis.

\section{References}

1. Kessler RC, Davis RB, Foster DF, et al. Long-term trends in the use of complementary and alternative medical therapies in the United States. Ann Intern Med. 2001;135:262-268.

2. Kaptchuk TJ. Acupuncture: theory, efficacy, and practice. Ann Intern Med. 2002;136:374-383, 1539-3704

3. Accreditation Commission for Acupuncture and Oriental Medicine (ACAOM). Accredited and Candidate Programs: May 2003. Available at: http://www.acaom.org/schoolistmay2003.htm. Accessed June 10, 2003.

4. Acupuncture and Oriental Medicine Alliance. List of States with statutes, regulations, and bills in progress. 2003. Available at: http:// www.aomalliance.org. Accessed June 9, 2003.

5. Eisenberg DM, Cohen MH, Hrbek A, Grayzel J, Van Rompay MI, Cooper RA. Credentialing complementary and alternative medical providers. Ann Intern Med. 2002;137:965-973.

6. Cherkin DC, Deyo RA, Sherman KJ, et al. Characteristics of visits to licensed acupuncturists, chiropractors, massage therapists, and naturopathic physicians. J Am Board Fam Pract. 2002;15:463-472.

7. Cherkin DC, Deyo RA, Sherman KJ, et al. Characteristics of licensed acupuncturists, chiropractors, massage therapists, and naturopathic physicians. J Am Board Fam Pract. 2002;15:378-390.

8. Schneider D, Appleton L, McLemore T. National Center for Health Statistics: A reason for visit classification for ambulatory care. In: DHEW Pub. No Public Health Service (PHS). Vital and Health Statistics. Washington, DC: US Government Printing Office; 1979:79-1352.

9. Birch SJ, Felt RL. Understanding Acupunture. New York, NY: Churchill Livingstone; 1999.

10. Wang KM, Yao SM, Xian YL, Hou ZL. A study on the receptive field of acupoints and the relationship between characteristics of needling sensation and groups of afferent fibres. Sci Sin [B]. 1985;28:963-971.

11. Melchart D, Linde $K$, Hager $S$, et al. Monitoring of liver enzymes in patients treated with traditional Chinese drugs. Complement Ther Med. 1999;7:208-216.

12. Kaptchuk T. The Web That Has no Weaver. 2nd ed. New York, NY: McGraw-Hill/Contemporary Books; 2000.

13. Vanherweghem J. Misuse of herbal remedies: the case of an outbreak of terminal renal failure in Belgium (Chinese herbs nephropathy). J Altern Complement Med. 1998;4:9-13.

14. Zhu YP. Toxicity of the Chinese herb mu tong (Aristolochia manshuriensis). What history tells us. Adverse Drug React Toxicol Rev. 2002;21:171-177.
15. Ernst E. Adulteration of Chinese herbal medicines with synthetic drugs: a systematic review. J Intern Med. 2002;252:107-113.

16. Ko RJ. Adulterants in Asian patent medicines. $N$ Engl J Med. 1998;339:847.

17. Au AM, Ko R, Boo FO, et al. Screening methods for drugs and heavy metals in Chinese patent medicines. Bull Environ Contam Toxicol. 2000;65:112-119.

18. Arnold MD, Thornbrough LM. Treatment of musculoskeletal pain with traditional Chinese herbal medicine. Phys Med Rehabil Clin N Am. 1999;10:663-671.

19. Bensoussan A, Myers SP, Drew AK, Whyte IM, Dawson AH. Development of a Chinese herbal medicine toxicology database. J Toxicol Clin Toxicol. 2002; 40:159-167.

20. Dale J. Acupuncture practicein the UK. Part 1: report of a survey. Complement Ther Med. 1997;5:215-220.

21. Diehl DL, Kaplan G, Coulter I, Glik D, Hurwitz EL. Use of acupuncture by American physicians. J Altern Complement Med. 1997;3:119-126.

22. Lee AC, Highfield ES, Berde CB, Kemper KJ. Survey of acupuncturists: practice characteristics and pediatric care. West J Med. 1999;171:153-157.

23. Mitchell BB. Acupuncture \& Oriental Medicine Laws-2001 Edition. Washington, DC: National Acupuncture Foundation; 2001.

24. Leake R, Broderick JE. Current licensure for acupuncture in the United States. Altern Ther Health Med. 1999;5:94-96.

25. Kalauokalani D, Cherkin D, Sherman KJ. A comparison of physician and non-physician acupuncture treatment for chronic low back pain. Clinical J Pain. In press.

26. Eisenberg DM, Davis RB, Ettner SL, et al. Trends in alternative medicine use in the United States, 1990-1997: results of a follow-up national survey. JAMA. 1998;280:1569-1575.

27. Xu X. Acupuncture in an outpatient clinic in China: a comparison with the use of acupuncture in North America. South Med J. 2001;94:813-816.

28. Melchart D, Linde K, Liao JZ, Hager S, Weidenhammer W. Systematic clinical auditing in complementary medicine: rationale, concept, and a pilot study. Altern Ther Health Med. 1997;3:33-39.

29. Sherman KJ. Characteristics and complaints of patients seeking therapy. J Altern Complement Med. 1997;3.212, 1075-5535.

30. Bullock ML, Pheley AM, Kiresuk TJ, Lenz SK, Culliton PD. Characteristics and complaints of patients seeking therapy at a hospital-based alternative medicine clinic. J Altern Complement Med. 1997;3:31-37.

31. Linde $K$, Vickers $A$, Hondras $M$, et al. Systematic reviews of complementary therapies - an annotated bibliography. Part 1: Acupuncture. BMC Complement Altern Med. 2001;1:3.

32. Vickers AJ. Can acupuncture have specific effects on health? A systematic review of acupuncture antiemesis trials. J $R$ Soc Med. 1996;89:303-311.

33. Shen J, Wenger N, Glaspy J, et al. Electroacupuncture for control of myeloablative chemotherapy-induced emesis: a randomized controlled trial. JAMA. 2000;284:2755-2761.

34. Melchart D, Linde K, Fischer $P$, et al. Acupuncture for idiopathic headache. Cochrane Database Syst Rev. 2001; CD001218.

35. Vickers AJ, Rees RW, Zollman CE, et al. Acupuncture for chronic headache in primary care: large, pragmatic, randomised trial. BMJ. 2004 doi:10.1136/bmj.38029.421863.EB (published 16 March 2004).

36. Ernst E, White AR. Acupuncture as a treatment for temporomandibular joint dysfunction: a systematic review of randomized trials. Arch Otolaryngol Head Neck Surg. 1999;125:269-272.

37. Kleinhenz J, Streitberger K, Windeler J, Gussbacher A, Mavridis G, Martin E. Randomised clinical trial comparing the effects of acupuncture and a newly designed placebo needle in rotator cuff tendinitis. Pain. 1999;83:235-241. 
38. Molsberger A, Mau J, Gotthardt H. German research of acupuncture for shoulder pain (GRASP)- does acupuncture contribute to the treatment of chronic pain (CSP). Presented at: the 10th Annual Meeting of the Society for Acupuncture Research, November 15-16, 2003; Boston, Mass.

39. Ernst $E$, White AR. Acupuncture for back pain: a meta-analysis of randomized controlled trials. Arch Intern Med. 1998;158:2235-2241.

40. Smith LA, Oldman AD, McQuay HJ, Moore RA. Teasing apart quality and validity in systematic reviews: an example from acupuncture trials in chronic neck and back pain. Pain. 2000;86:119-132.

41. van Tulder MW, Cherkin DC, Berman B, Lao L, Koes BW. The effectiveness of acupuncture in the management of acute and chronic low back pain. A systematic review within the framework of the Cochrane Collaboration Back Review Group. Spine. 1999;24:1113. 1123.

42. Cherkin DC, Sherman KJ, Deyo RA, Shekelle PG. A review of the evidence for the effectiveness, safety, and cost of acupuncture, massage therapy, and spinal manipulation for back pain. Ann Intern Med. 2003;138:898-906

43. Molsberger AF, Mau J, Pawelec DB, Winkler J. Does acupuncture improve the orthopedic management of chronic low back pain: a randomized, blinded, controlled trial with 3 months follow up. Pain. 2002;99:579-587.

44. Meng CF, Wang D, Ngeow J, Lao L, Peterson M, Paget S. Acupuncture for chronic low back pain in older patients: a randomized, controlled trial. Rheumatology (Oxford). 2003;42:1508-1517.

45. Irnich D, Behrens N, Molzen H, et al. Randomised trial of acupuncture compared with conventional massage and "sham" laser acupuncture for treatment of chronic neck pain. BMJ. 2001;322:15741578.

46. Kalauokalani D, Cherkin DC, Sherman KJ, Koepsell TD, Deyo RA. Lessons from a trial of acupuncture and massage for low back pain: patient expectations and treatment effects. Spine. 2001;26:1418-1424.
47. Berman BM. Seminal studies in acupuncture research. J Altern Complement Med. 2001;Suppl 1:S129-S137.

48. Cherkin, DC. Efficacy of acupuncture for chronic low back pain. 2003. Available at: http://www.clinicaltrials.gov/ct/show/NCT00065585.

49. Molsberger A, Bowing G, Haake M, Meier U, Winkler J, Molsberger $\mathrm{F}$. Acupuncture in the treatment of locomotive disorders - status of research and situation regarding clinical application. Schmerz. 2002; 16:121-128.

50. Thomas KJ, Fitter M, Brazier J, et al. Longer-term clinical and economic benefits of offering acupuncture to patients with chronic low back pain assessed as suitable for primary care management. Complement Ther Med. 1999:7:91-100.

51. Ernst E, White AR. Prospective studies of the safety of acupuncture: a systematic review. Am J Med. 2001;110:481-485.

52. MacPherson H, Thomas K, Walters S, Fitter M. The York acupuncture safety study: prospective survey of 34,000 treatments by traditional acupuncturists. BMJ. 2001;323:486-487.

53. White A, Hayhoe S, Hart A, Ernst E. Adverse events following acupuncture: prospective survey of 32,000 consultations with doctors and physiotherapists. BMJ. 2001;323:485-486.

54. May B. The risks associated with TCM: a review and disucssion of the literature. Pacific J Oriental Med. 1997;10:30-44.

55. De Smet PA. Herbal remedies. N Engl J Med. 2002;347:2046-2056.

56. Bensoussan A, Myers SP, Carlton AL. Risks associated with the practice of traditional Chinese medicine: an Australian study. Arch Fam Med. 2000;9:1071-1078.

57. De Smet PA. Health risks of herbal remedies. Drug Saf. 1995;13:81-93.

58. Eisenberg DM . Advising patients who seek alternative medical therapies. Ann Intern Med. 1997;127:61-69. 